\title{
Cellulolytic and Xylanolytic Microbial Communities Associated With Lignocellulose-Rich Wheat Straw Degradation in Anaerobic Digestion
}

OPEN ACCESS

Edited by:

Madalena Santos Alves, University of Minho, Portugal

Reviewed by:

Wensheng Qin,

Lakehead University, Canada

Peng Guo,

Hubei Academy of Agricultural Sciences, China

*Correspondence:

Michael Vedel Wegener Kofoed mvk@bce.au.dk

tThese authors have contributed equally to this work and share first authorship

Specialty section:

This article was submitted to Microbiological Chemistry and Geomicrobiology, a section of the journal Frontiers in Microbiology

Received: 22 December 2020 Accepted: 19 April 2021

Published: 25 May 2021

Citation:

Jensen MB, de Jonge $N$, Dolriis $\mathrm{MD}$, Kragelund $\mathrm{C}$, Fischer $\mathrm{CH}$, Eskesen MR, Noer K, Møller HB,

Ottosen LDM, Nielsen $\mathrm{J}$ and Kofoed MWW (2021) Cellulolytic

and Xylanolytic Microbial

Communities Associated With Lignocellulose-Rich Wheat Straw Degradation in Anaerobic Digestion.

Front. Microbiol. 12:645174. doi: 10.3389/fmicb.2021.645174
Mads Borgbjerg Jensen ${ }^{1+}$, Nadieh de Jonge ${ }^{2,3 \dagger}$, Maja Duus Dolriis ${ }^{1}$, Caroline Kragelund ${ }^{4}$, Christian Holst Fischer ${ }^{4}$, Martin Rosenørn Eskesen ${ }^{4}$, Karoline Noer ${ }^{1}$, Henrik Bjarne Møller ${ }^{1}$, Lars Ditlev Mørck Ottosen'1, Jeppe Lund Nielsen² and Michael Vedel Wegener Kofoed ${ }^{1 *}$

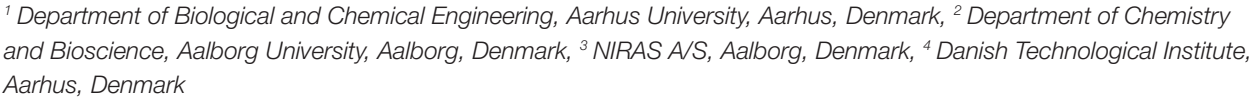

${ }^{1}$ Department of Biological and Chemical Engineering, Aarhus University, Aarhus, Denmark, ${ }^{2}$ Department of Chemistry and Bioscience, Aalborg University, Aalborg, Denmark, ${ }^{3}$ NIRAS A/S, Aalborg, Denmark, ${ }^{4}$ Danish Technological Institute, Aarhus, Denmark

The enzymatic hydrolysis of lignocellulosic polymers is generally considered the ratelimiting step to methane production in anaerobic digestion of lignocellulosic biomass. The present study aimed to investigate how the hydrolytic microbial communities of three different types of anaerobic digesters adapted to lignocellulose-rich wheat straw in continuous stirred tank reactors operated for 134 days. Cellulase and xylanase activities were monitored weekly using fluorescently-labeled model substrates and the enzymatic profiles were correlated with changes in microbial community compositions based on 16S rRNA gene amplicon sequencing to identify key species involved in lignocellulose degradation. The enzymatic activity profiles and microbial community changes revealed reactor-specific adaption of phylogenetically different hydrolytic communities. The enzymatic activities correlated significantly with changes in specific taxonomic groups, including representatives of Ruminiclostridium, Caldicoprobacter, Ruminofilibacter, Ruminococcaceae, Treponema, and Clostridia order MBA03, all of which have been linked to cellulolytic and xylanolytic activity in the literature. By identifying microorganisms with similar development as the cellulase and xylanase activities, the proposed correlation method constitutes a promising approach for deciphering essential cellulolytic and xylanolytic microbial groups for anaerobic digestion of lignocellulosic biomass.

Keywords: anaerobic digestion, hydrolysis, microbial community, microbial adaptation, lignocellulose, fluorometric enzyme assay, biogas, wheat straw

Abbreviations: ASV, Amplicon Sequence Variant; CA, Correspondence Analysis; COD, Chemical Oxygen Demand; CSTR, Continuous Stirred Tank Reactor; HRT, Hydraulic retention time; MPR, Methane Production Rate; NGS, Next-generation sequencing; OLR, Organic loading rate; RDA, Redundancy Analysis; TS, Total solids; VFA, Volatile Fatty Acid; VS, Volatile solids. 


\section{INTRODUCTION}

Anaerobic digestion is a well-known biological process for handling and upcycling different waste streams and biomasses to a renewable methane-rich biogas and digestate-fertilizer (Weiland, 2010). The installed global biogas capacity is continuously expanding (Scarlat et al., 2018), and biomethane is expected to be an essential energy source in the fossilfree energy system (Wall et al., 2018). Feedstocks for biogas production are mainly based on low-cost organic waste streams like manure, sludge, and organic household waste. Lignocellulosic residues from the agricultural sector, such as deep litter and straw residues, constitute a highly abundant type of biomass whose use in anaerobic digestion is essential to realize the technology's full societal potential for renewable methane production (Sawatdeenarunat et al., 2015). However, the recalcitrant structure of lignocellulose protects the cellulosic and hemicellulosic polymers from microbial degradation and constitutes an economic and technical barrier to anaerobic digestion of lignocellulosic biomasses. Anaerobic digestion of lignocellulosic biomasses consequently relates to low methane production rates (MPRs), entailing long solid retention times or excessive reactor volume to obtain high methane yields (Achinas et al., 2017). Microbially secreted hydrolases catalyze the initial hydrolysis of cellulosic and hemicellulosic polymers, which is considered the rate-limiting step in anaerobic digestion of recalcitrant lignocellulosic substrates (Noike et al., 1985; Sambusiti et al., 2014). Most research has consequently focused on developing pretreatment strategies that accelerate the biological degradation of lignocellulose by breaking up the recalcitrant structure and exposing the cellulosic and hemicellulosic polymers to enzymatic attack (Ahring et al., 2015; Feng et al., 2017). The MPRs and methane yields from cellulosic and lignocellulosic biomass depend on the origin of the inoculum, as the specific microbial community, activity, and ability to adapt to lignocellulosic biomass degradation is shaped by the operating conditions applied in the anaerobic digester (Sun et al., 2016; Koch et al., 2017; Liu et al., 2017). Obtaining a more thorough understanding of the involved microbial and functional dynamics during anaerobic digestion of lignocellulosic biomass can potentially promote methane production directly in the anaerobic digester and reduce the need for costly pretreatment technologies accordingly (Hu et al., 2011).

High-throughput next-generation sequencing techniques such as $16 \mathrm{~S}$ rRNA gene amplicon sequencing have provided tools to characterize the microbial communities in anaerobic digesters in terms of phylogeny and potential functions, enabling monitoring of changes in the microbial communities in response to different operational conditions (de Jonge et al., 2017, 2020). These properties have fueled the idea of developing microbial control systems and optimizing the conventional anaerobic digestion process based on the identification of microbial process indicators (Carballa et al., 2015; De Vrieze, 2020). The development of microbial-based control strategies is still troubled by the significant shortage of fundamental knowledge on the active microbial community and microbial indicators, which are influenced by a range of process conditions
(De Vrieze et al., 2018). Firstly, a large part of the microbiome in anaerobic digesters is still unknown and therefore only classified on higher taxonomic ranks (Campanaro et al., 2016). Secondly, potential functions indicated by metagenomic analyses do not necessarily translate into important operational parameters describing substrate turnover (Hassa et al., 2018). Different approaches are being developed to decipher the active microbiome, e.g., using multi-omics approaches (Mosbæk et al., 2016; De Vrieze et al., 2018), or microbial fingerprinting techniques to map the presence or expression of specific genes (Zhang et al., 2014; Müller et al., 2016). Combining bulk activity tests, such as organic degradation and methane production rates, with microbial community data has also been shown as a promising approach for identifying microbial groups important to the degradation of specific substrates (Regueiro et al., 2012). Cellulolytic bacteria have been identified at different phylogenetic levels by correlating degradation rates of lignocellulosic straw and cellulose with changes in specific genes encoding hydrolases involved in cellulose degradation (Sun et al., 2016). This study uses a new approach to identify potential key microbial communities involved in lignocellulose hydrolysis in anaerobic digestion by correlating changes in microbial community structures directly to changes in cellulase and xylanase activities. Cellulases and xylanases catalyze the hydrolysis of cellulose and xylan (hemicellulose), respectively, which are abundant lignocellulosic polymers. The hydrolytic bacterial community expressing these enzymes is consequently of particular importance to the MPR during anaerobic digestion of lignocellulosic material.

The objective of the present study was to investigate (i) how different types of digestate inocula respond and adapt to increased feeding with lignocellulose-rich wheat straw, based on changes in microbial community structures, activities of cellulase and xylanase, and the MPR; and from these data (ii) identify potential hydrolytic microorganisms by correlating the enzymatic activities and the microbial community compositions. Mixtures of wheat straw and inoculum-specific biomass material were used as model substrate and fed to lab-scale CSTRs inoculated with digestate from different manure- and sludgebased full-scale digesters. The hydrolytic adaptation was characterized for three different inoculum types to demonstrate the broad applicability of the proposed correlation method.

\section{MATERIALS AND METHODS}

\section{Inoculum Characterization}

Digestates from three different full-scale digesters were used as inocula in lab-scale reactors within few hours after their collection at the plants. All biomasses were sieved through a $1 \mathrm{~mm}$ mesh prior to inoculation and subject to an acclimation period of 11 days before the period of straw-feeding (section "Reactor Operation"). The inocula were expected to have different capabilities for degrading lignocellulosic substrates, reflected by the differences in substrate types and operational conditions of the full-scale digesters (Table 1). R1 (Aarhus University Foulum, Denmark) was expected to be highly adapted to digest 
lignocellulosic biomass since it was operated at thermophilic conditions and its primary substrates included cattle, and pig manure as well as straw and deep litter. R2 (Maabjerg Energy Center, Denmark) treated a larger mix of biomasses, including industrial waste, cattle, and pig manure, and deep litter. R3's (Billund Vand and Energi, Denmark) primary substrates were pre-treated sludge and industrial waste. R2 and R3 were both operated at mesophilic temperatures.

\section{Reactor Operation}

Six continuous stirred tank reactors (CSTR) (1.8 L working volume, $2 \mathrm{~L}$ total volume) (Bioprocess Control AB, Sweden) were operated anaerobically for 134 days. The lab-scale reactors were operated in duplicates and inoculated with digestates from either R1, R2, or R3 using temperature conditions similar to the full-scale systems (Table 1). The feeding period started on day 11 and ended on day 81 . The hydraulic retention time (HRT) was 20 days, and the reactors were fed three times per week using mixtures of degassed reactor-specific slurry material and wheat straw. The wheat straw was down-sized $(<10 \mathrm{~mm})$ using a hammer mill. Its fiber composition was determined previously as a percentage of dry weight: hemicellulose $30.4 \pm 0.8$ $\mathrm{w} \%$, cellulose $44.8 \pm 0.8 \mathrm{w} \%$, and lignin $7.2 \pm 0.5 \mathrm{w} \%$. The organic loading rate (OLR) was defined solely based on the wheat straw and initially set to $2.0 \mathrm{~g}$ volatile solids (VS) $\cdot \mathrm{L}^{-1} \cdot$ day $^{-1}$, but increased to $3.0 \mathrm{~g} \cdot \mathrm{VS} \cdot \mathrm{L}^{-1} \cdot$ day $^{-1}$ from day 32, i.e., after one HRT. Stirring and temperature

TABLE 1 | Operational information of the sampled full-scale digesters and the physiochemical characteristics of the biomass samples used as inoculum in the lab-scale reactors.

\begin{tabular}{|c|c|c|c|}
\hline $\begin{array}{l}\text { Operational } \\
\text { parameters }\end{array}$ & R1 & $\mathbf{R} 2$ & R3 \\
\hline $\begin{array}{l}\text { Hydraulic retention } \\
\text { time (d) }\end{array}$ & 13 & 26 & 30 \\
\hline $\begin{array}{l}\text { Organic loading rate } \\
\left(\mathrm{kg} \mathrm{VS} \cdot \mathrm{m}^{-3} \cdot \mathrm{d}^{-1}\right)\end{array}$ & 8 & 2.5 & n.a. \\
\hline Reactor volume $\left(\mathrm{m}^{3}\right)$ & 1,200 & 3,750 & 2,800 \\
\hline Methane content (\%) & 58 & 61 & 69 \\
\hline $\begin{array}{l}\text { Methane production } \\
\text { rate } \\
\left(\mathrm{m}^{3} \cdot \mathrm{m}^{-3} \cdot \mathrm{d}^{-1}\right)\end{array}$ & 2.2 & 0.8 & 1.6 \\
\hline Temperature $\left({ }^{\circ} \mathrm{C}\right)$ & 52 & 37 & 37 \\
\hline Substrates & $\begin{array}{l}\text { Cattle manure } \\
\text { Pig manure, } \\
\text { Deep litter } \\
\text { Straw } \\
\text { Grasses }\end{array}$ & $\begin{array}{l}\text { Industrial waste } \\
\text { Cattle manure } \\
\text { Pig manure } \\
\text { Deep litter } \\
\text { Straw }\end{array}$ & $\begin{array}{l}\text { Sewage sludge } \\
\text { Municipal waste } \\
\text { Industrial waste }\end{array}$ \\
\hline Inoculum & $\mathrm{R} 1$ & $\mathrm{R} 2$ & R3 \\
\hline TS (\%) & $3.9 \pm 0.0$ & $3.3 \pm 0.2$ & $3.6 \pm 0.0$ \\
\hline VS (\%) & $2.8 \pm 0.0$ & $2.2 \pm 0.1$ & $2.4 \pm 0.0$ \\
\hline $\operatorname{VFA}\left(\mathrm{mg} \cdot \mathrm{L}^{-1}\right)$ & $248 \pm 14$ & $677 \pm 96$ & $727 \pm 9$ \\
\hline $\mathrm{NH}_{4}+\left(g \cdot L^{-1}\right)$ & $1.5 \pm 0.01$ & $3.9 \pm 0.4$ & $2.0 \pm 0.01$ \\
\hline $\operatorname{COD}\left(g \cdot L^{-1}\right)$ & $45.2 \pm 11.4$ & $35.6 \pm 8.8$ & $25.8 \pm 4.6$ \\
\hline $\mathrm{pH}$ & $7.5 \pm 0.1$ & $7.6 \pm 0.1$ & $7.4 \pm 0.0$ \\
\hline
\end{tabular}

n.a. = not available remained constant for another 64 days after the feeding period had ended to study the influence of starvation on enzymatic activities. Methane production was monitored continuously using the AMPTS II (Bioprocess Control AB, Sweden). MPR is presented with units of $\mathrm{L} \cdot \mathrm{L}^{-1} \cdot \mathrm{day}^{-1}$ and shown as a weekly average to even out fluctuations in gas production caused by the discontinuous feeding three times per week. Samples for physicochemical and microbial community characterizations were withdrawn at weekly intervals and stored at $-20^{\circ} \mathrm{C}$ until further analysis.

\section{Physicochemical Reactor Characterizations}

Total solids (TS) and volatile solids (VS) were determined according to standard procedures (Rice et al., 2017). Chemical oxygen demand (COD) and ammonium concentrations $\left(\mathrm{NH}_{4}{ }^{+}\right)$were determined using commercial kits according to the manufacturer's protocol ( $\mathrm{HACH}^{\circledR}$, Germany). Volatile fatty acid (VFA) concentrations were determined using gas chromatography equipped with a HP-INNOWAX column (30 m, $0.25 \mathrm{~mm}, 0.25 \mu \mathrm{m}$ ) (Agilent Technologies) and a flame ionization detector using helium as carrier gas.

\section{Cellulase and Xylanase Activities}

The activities of extracellular cellulases and xylanases were consistently determined in one of the duplicate reactors for R1, R2, and R3. The enzymatic activities were determined every week during the period with organic feeding (day 1181) and three times in the subsequent starvation period (day 82-145). Enzyme activities were determined using a fluorometric assay, where slurry samples from the individual reactors were incubated with 4-methylumbelliferone (MUF)linked cellobioside and xylopyranoside compounds (SigmaAldrich, Denmark). Specifically, 4-methylumbelliferyl $\beta$-Dcellobioside (MUF-cellobioside), and 4-methylumbelliferyl- $\beta$-Dxylopyranoside (MUF-xylopyranoside) were used as fluorometric substrates that resemble breakdown products of polymeric cellulose and xylan, respectively. MUF-labeled substrate analogs have previously been used to analyze hydrolase activities in different environmental systems, including wetlands (Freeman et al., 1995), soil (Darrah and Harris, 1986), and sediments (King, 1986), and was here adopted for the biogas process. Preliminary incubations with commercial enzymes showed that MUF-cellobioside was hydrolyzed mainly by endoglucanases and to a minor extent by $\beta$-glucosidase. MUF-xylopyranoside was hydrolyzed mainly by $\beta$-xylosidase and to a minor extent by endoglucanase (Data not shown).

Slurry was withdrawn from the laboratory biogas reactor and prepared for enzymatic analyses by homogenizing the sample with a high-speed dispersing instrument ( $\mathrm{T} 10$ basic Ultra Turrax; IKA). The remaining non-pipettable particulates were removed by centrifugation at $300 \times \mathrm{g}$ for $60 \mathrm{~s}$ and filtering (800 $\mu \mathrm{m}$ mesh). Before the addition of the MUFlinked substrates, the homogenized slurry was diluted in $50 \mathrm{mM}$ Tris- $\mathrm{HCl}(\mathrm{pH} 7.5)$ to a final concentration of 0.5 or $1 \%$ for (i) analyzing conversion of the MUF-linked substrates at 
non-substrate limiting conditions $\left(\mathrm{V}_{\max }\right)$; while (ii) avoiding MUF concentrations exceeding the linear range of the MUF standard curve (due to high rates of hydrolysis). The two MUF-labeled model substrates were added to individual slurry samples in two concentrations to assess if the hydrolysis rates were independent of substrate concentrations. The final concentration was 0.28 and $0.14 \mathrm{mmol} \cdot \mathrm{L}^{-1}$ for MUFcellobioside, and 0.11 and $0.06 \mathrm{mmol} \cdot \mathrm{L}^{-1}$ for MUFxylopyranoside. Negative controls were prepared by heatinactivating the slurry at $100^{\circ} \mathrm{C}$ for $10 \mathrm{~min}$ prior to the homogenization step described above. The water lost due to evaporation was added to the slurry after boiling. MUF standards were prepared in both active and heat-inactivated slurry samples. These standards were analyzed along with both active samples and the negative controls.

All samples were transferred to a black flat-bottomed 96well microplate (Greiner Bio-One, Germany) and analyzed in duplicates at reactor-specific temperatures using a microplate reader system (Varioskan LUX, Thermo Fischer Scientific Inc., United States). Excitation and emission wavelengths of MUF were 355 and $445 \mathrm{~nm}$, respectively, and fluorescence from released MUF was measured every fifth minute for at least $2 \mathrm{~h}$. Hydrolase activities are reported as the initial linear hydrolysis rate (zero-order kinetics), averaged for the two substrate concentrations.

It is important to note that the enzymatic activity in $\mathrm{R} 1$ was assayed at $45^{\circ} \mathrm{C}$, despite reactor operation at $52^{\circ} \mathrm{C}$. This discrepancy was due to a temperature constraint of the plate reader incubator. The actual enzymatic activities of R1 were, therefore, likely higher than measured here due to kinetic effects. Samples from R2 and R3 were analyzed at $37^{\circ} \mathrm{C}$, similar to reactor conditions.

\section{DNA Extraction and 16S rRNA Gene Amplicon Sequencing}

Slurry samples were withdrawn for DNA sequencing on a weekly basis throughout the feeding period. Genomic DNA was extracted from $300 \mu \mathrm{L}$ of digester slurry using the FastDNA ${ }^{\mathrm{TM}}$ SPIN Kit for Soil (MP Biomedicals, Inc.) according to the manufacturer's recommendation with minor alterations; beadbeating was performed in 4 cycles of $40 \mathrm{~s}$ at $6 \mathrm{~m} \cdot \mathrm{s}^{-1}$, and elution was performed in $60 \mu \mathrm{L}$ DES buffer. DNA quantity and quality were assessed using a Qubit 2.0 fluorometer with Qubit dsDNA BR Assay kit (Thermo Fisher Scientific, United States) and TapeStation 2200 with Genomic DNA ScreenTapes (Agilent, United States). The V4 region of the 16S rRNA gene was amplified as previously described (Albertsen et al., 2015). Obtained libraries were purified using the AMPure XP bead protocol with a sample:bead ratio of 0.8 (Beckmann Coulter, United States). Library quantity and quality were determined using Quant-iT dsDNA HS Assay Kit (Thermo Fischer Scientific, United States) and D1000 ScreenTapes (Agilent, United States). The libraries were sequenced on a MiSeq (Illumina, United States) in equimolar concentrations using reagent kit v2 $(1 \times 300)$. The raw sequencing data was processed into amplicon sequencing variants (ASVs) using the
AmpProc pipeline (version 5.1) ${ }^{1}$ in single read mode. Taxonomy was assigned using MiDAS (v4.6) as the reference database (McIlroy et al., 2017).

\section{Data Analysis}

$\mathrm{R}$ version 3.6.1 ( $\mathrm{R}$ Core Team, 2016) and RStudio version 1.2.5001 ${ }^{2}$ were used for all statistical and microbial community analyses. Alpha diversity was measured using the Chaol (Chao, 1984) and Shannon-Weaver (Shannon, 1948) indices, and beta diversity was visualized using correspondence analysis (CA). Microbial compositions were visualized using heatmaps. The overall link between the microbial community development and the enzymatic activities was investigated using Redundancy Analysis (RDA). ASVs with a strong link to the enzymatic activities were extracted from the dataset as follows: All ASVs were subjected to the Kolmogorov-Smirnov test (Massey, 1951) to select ASVs with a distribution similar to that of the measured enzymatic activities. The ASVs with the strongest relationship to the enzymatic rates were selected as hydrolytic candidates based on a subsequent linear regression analysis of the relative abundances of the selected ASVs, normalized by the enzymatic activity. Pearson's correlations were used to correlate operational parameters. All other visualizations were generated using ggplot2 (Wickham, 2016).

\section{RESULTS}

\section{Performance of Laboratory Reactors}

The thermophilic R1 exhibited the highest MPR compared to the mesophilic R2 and R3 throughout the feeding period (day 1181) (Figure 1). The MPR in R1 was $0.45 \pm 0.07 \mathrm{~L} \cdot \mathrm{L}^{-1} \cdot \mathrm{d}^{-1}$ during the first week of operation (day 11-17), corresponding to a 62 and $15 \%$ higher MPR compared to those in R2 and $\mathrm{R} 3$, respectively. The MPR in R1 was $20 \%$ (R2) and $13 \%$ (R3) higher in the last week of the feeding period (day 74-80), where it amounted to $0.63 \pm 0.05 \mathrm{~L} \cdot \mathrm{L}^{-1} \cdot \mathrm{d}^{-1}$ in $\mathrm{R} 1$ compared to $0.53 \pm 0.05 \mathrm{~L} \cdot \mathrm{L}^{-1} \cdot \mathrm{d}^{-1}$ and $0.56 \pm 0.05 \mathrm{~L} \cdot \mathrm{L}^{-1} \cdot \mathrm{d}^{-1}$ in R2 and R3, respectively. Among the mesophilic reactors, R2 and R3, the former exhibited a lower MPR during the first 14 days of operation (day 11-24). However, R2 and R3 exhibited similar MPRs from the third week of operation (day 25-31) and throughout the remaining experimental period.

An initial lag phase was observed in all reactors, evidenced by the consistent increases in MPRs during the first 1.5 HRT (day 11-38) (Figure 1). The MPR increased by 56, 109, and $45 \%$ in R1, R2, and R3, respectively, between days 11-18 (week 1 of feeding) and days 32-38 (week 4). The OLR was $2.0 \mathrm{~g}$ VS $\cdot \mathrm{L}^{-1} \cdot$ day $^{-1}$ up to and including day 31 (i.e., the first HRT) and increased to $3.0 \mathrm{~g}$ VS $\cdot \mathrm{L}^{-1} \cdot$ day $^{-1}$ hereafter to push adaptation of the hydrolytic community further. The increase in OLR was accompanied by increases in the MPRs only in the first week (days 32-38), followed by a decreasing trend for all reactors in the following weeks. However, the decrease in

\footnotetext{
${ }^{1}$ https://github.com/eyashiro/AmpProc

${ }^{2}$ https://www.rstudio.com/
} 


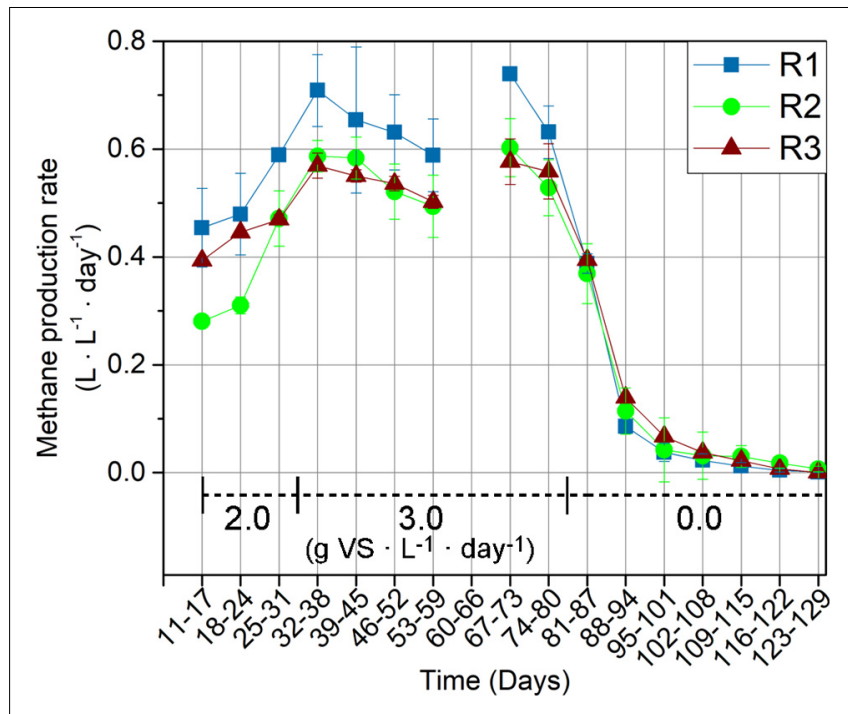

FIGURE 1 | Methane production rates for the thermophilic reactor (R1), and mesophilic reactors (R2 and R3). MPRs are presented as weekly average. The reactors were fed with wheat straw from day 11-81 and organic loading rates ( $\mathrm{g} V \mathrm{~S} \cdot \mathrm{L}^{-1} \cdot$ day $^{-1}$ ) are indicated on the graph. The MPR was not recorded during days $60-66$ due to a technical error.

MPR was not permanent. The MPRs thus increased towards the end of the feeding period, which ended at day 81. MPRs during days 60-66 were not recorded due to technical issues. Overall, the $50 \%$ increase in OLR at day 32 resulted in MPR increases of 7,12 , and $19 \%$ in $\mathrm{R} 1, \mathrm{R} 2$, and $\mathrm{R} 3$, respectively, when comparing the final week of feeding (days 74-80) with the period before the OLR increase (days 25-31). The MPR decreased significantly in all reactors after feeding was stopped at day 81 (Figure 1).

The stable performance of $\mathrm{R} 1$ was also indicated from process indicators in the digestate, where $\mathrm{pH}, \mathrm{VFAs}$, and the COD remained relatively stable (Table 2 ). $\mathrm{pH}$ values were $7.3 \pm 0.2$ in $\mathrm{R} 1$ and $\mathrm{R} 2$ and $7.1 \pm 0.2$ in R3 throughout the experiment. In $\mathrm{R} 2$, the reactor subjected to the most significant increase in MPR, VFA levels increased throughout the experimental period, from $656 \pm 94 \mathrm{mg} \cdot \mathrm{L}^{-1}$ at day 18 to $2,563 \pm 812 \mathrm{mg} \cdot \mathrm{L}^{-1}$ at the last day of feeding (day 81 ). The COD in R2 increased from $28.9 \pm 6.2 \mathrm{~g} \cdot \mathrm{L}^{-1}$ at day 18 to $39.2 \pm 4.9 \mathrm{~g} \cdot \mathrm{L}^{-1}$ at day 81 . In R3, there was a temporary increase in VFA levels around day 62. The COD in $\mathrm{R} 3$ increased from $25.3 \pm 2.5 \mathrm{~g} \cdot \mathrm{L}^{-1}$ on day 18 to $35.6 \pm 5.6 \mathrm{~g} \cdot \mathrm{L}^{-1}$ on day 81 , similar to the final COD in R1 (Table 2).

\section{Cellulase and Xylanase Activities in Laboratory Reactors}

The cellulase (Figure 2A) and xylanase (Figure 2B) activities were initially highest in the thermophilic R1, supporting its higher MPR compared to the mesophilic reactors, R2 and R3 (Figure 1). The initial enzymatic activities in R1 were thus 5.9 (cellulase) and 10.0 (xylanase) times higher compared to the activities in R2, and 3.2 (cellulase) and 7.9 (xylanase) times higher than the activities in R3. The enzymatic activities in
R1 were likely even higher than measured since the enzymatic analysis was technically constrained to $45^{\circ} \mathrm{C}$, whereas R1's operating temperature was $52^{\circ} \mathrm{C}$. Furthermore, the xylanase activity measurements in $\mathrm{R} 1$ were not determined at $\mathrm{V}_{\max }$ conditions, explaining the higher standard deviations for these measurements. The actual differences between the xylanase activities in R1 and the two mesophilic reactors are hence likely to be larger than measured here (Figure 2B).

Cellulase. The largest increases in cellulase activity were observed in R2 and R3. The cellulase activity in R3 increased immediately after the experimental start and continued until day 41 (corresponding with 1.5 HRT), where it was 7.9-fold higher compared to the initial measurement (Figure 2A). The cellulase activity in R2 showed a slower response compared to R3. Compared to R3, the R2 cellulase activity increase was modest during the first hydraulic retention time with straw feedings (days 11-34). However, the increase in OLR from 2.0 to $3.0 \mathrm{~g}$ $\mathrm{VS} \cdot \mathrm{L}^{-1} \cdot$ day $^{-1}$ at day 32 coincided with a significant increase in $\mathrm{R} 2$ cellulase activity in the following period. The R2 cellulase activity peaked at day 62 (corresponding to 2.5 HRT) with $70.4 \pm 8.8 \mathrm{mg} \mathrm{MUF} \cdot \mathrm{L}^{-1} \cdot \mathrm{h}^{-1}$, equivalent to a 17.4 -fold increase compared to the initial activity. Despite the consistent increase in MPR by $56 \%$ (Figure 1), the R1 cellulase activity remained relatively stable during the first 28 days of straw feeding (day 11-39). However, the activities in R1 increased to 1.5-2.4 times the initial cellulase activity in the subsequent period (day 4667) before declining to $84-90 \%$ of the original activity in the last week of feeding (days 74 and 81). R2 and R3 were subject to similar decreases in cellulase activity within the feeding period, but the onset varied. R3 cellulase activity started to decline after day 41 (corresponding to HRT 1.5), while the decrease in activity in R1 and R2 started after day 60 and 62 (corresponding to HRT $2.5)$, respectively.

Xylanase. The xylanase activities in $\mathrm{R} 1$ remained within 62$110 \%$ of the initial activity during the first 35 days (days 11-46) of

TABLE 2 | Physicochemical parameters of effluent samples from the duplicate lab-scale reactors.

\begin{tabular}{|c|c|c|c|c|c|}
\hline \multicolumn{6}{|l|}{ R1 } \\
\hline Day & 18 & 41 & 62 & 81 & 141 \\
\hline $\mathrm{pH}$ & $7.4 \pm 0.0$ & $7.2 \pm 0.0$ & $7.2 \pm 0.0$ & $7.1 \pm 0.1$ & $8.2 \pm 0.0$ \\
\hline $\operatorname{VFA}\left(\mathrm{mg} \cdot \mathrm{L}^{-1}\right)$ & $310 \pm 70$ & $273 \pm 41$ & $324 \pm 12$ & $450 \pm 60$ & - \\
\hline $\mathrm{NH}_{4}+\left(\mathrm{g} \cdot \mathrm{L}^{-1}\right)$ & $1.2 \pm 0.04$ & $0.6 \pm 0.05$ & $0.4 \pm 0.01$ & $0.4 \pm 0.01$ & - \\
\hline $\operatorname{COD}\left(g \cdot L^{-1}\right)$ & $44.9 \pm 4.2$ & $35.1 \pm 5.1$ & $34.8 \pm 4.8$ & $35.7 \pm 3.3$ & - \\
\hline \multicolumn{6}{|l|}{$\mathbf{R} 2$} \\
\hline $\mathrm{pH}$ & $7.5 \pm 0.0$ & $7.3 \pm 0.1$ & $7.3 \pm 0.1$ & $7.2 \pm 0.0$ & $7.9 \pm 0.0$ \\
\hline $\operatorname{VFA}\left(\mathrm{mg} \cdot \mathrm{L}^{-1}\right)$ & $656 \pm 94$ & $1,232 \pm 505$ & $1,345 \pm 90$ & $2,563 \pm 812$ & - \\
\hline $\mathrm{NH}_{4}+\left(\mathrm{g} \cdot \mathrm{L}^{-1}\right)$ & $2.7 \pm 0.0$ & $1.4 \pm 0.05$ & $1.1 \pm 0.2$ & $1.2 \pm 0.1$ & - \\
\hline $\operatorname{COD}\left(g \cdot L^{-1}\right)$ & $28.9 \pm 6.2$ & $31.0 \pm 0.9$ & $30.1 \pm 2.4$ & $39.2 \pm 4.9$ & - \\
\hline \multicolumn{6}{|l|}{ R3 } \\
\hline $\mathrm{pH}$ & $7.3 \pm 0.1$ & $7.0 \pm 0.0$ & $7.0 \pm 0.0$ & $6.9 \pm 0.0$ & $7.9 \pm 0.0$ \\
\hline $\operatorname{VFA}\left(\mathrm{mg} \cdot \mathrm{L}^{-1}\right)$ & $649 \pm 127$ & $680 \pm 18$ & $2,138 \pm 1,106$ & $668 \pm 43$ & - \\
\hline $\mathrm{NH}_{4}+\left(\mathrm{g} \cdot \mathrm{L}^{-1}\right)$ & $1.5 \pm 0.03$ & $0.8 \pm 0.04$ & $0.6 \pm 0.0$ & $0.4 \pm 0.0$ & - \\
\hline $\operatorname{COD}\left(g \cdot L^{-1}\right)$ & $25.3 \pm 2.5$ & $34.9 \pm 4.4$ & $32.6 \pm 0.0$ & $35.6 \pm 5.6$ & - \\
\hline
\end{tabular}

$R 1$ is thermophilic and $R 2$ and $R 3$ are mesophilic reactors. 

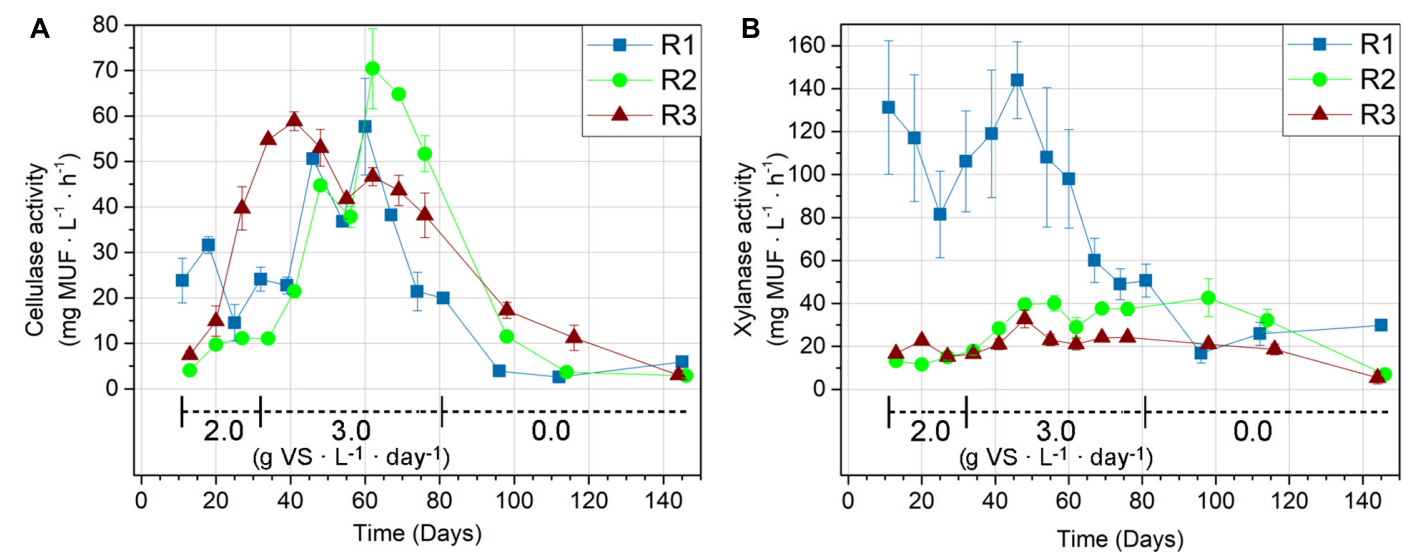

FIGURE 2 | Cellulase (A) and xylanase (B) activities given by MUF release rate in the thermophilic R1, and the mesophilic reactors R2 and R3. The reactors were fed with wheat straw from day $11-81$ and organic loading rates $\left(\mathrm{g}\right.$ VS $\cdot \mathrm{L}^{-1} \cdot$ day ${ }^{-1}$ ) are indicated on the graphs.

straw feeding (Figure 2B). The R1 xylanase activity was 8-10-fold higher than in R2 and R3 for the first measurement. However, the R1 xylanase activity started declining after day 46, ending at $37 \%$ of its initial activity on the last day of feeding (day 81 ). For the mesophilic reactors, the xylanase activity increased more pronouncedly in R2 compared to R3, stabilizing at $\sim 3$-fold and 1.5 -fold gains in the feeding period, respectively, compared to the initial measurements. The xylanase activities in R2 and R3 did not decrease until the starvation period, which began on day 81 .

Response to starvation. The cellulase and xylanase activities generally declined after the feeding period ended (day 81 and onward), but the development was both enzyme- and reactordependent. The cellulase activities continued to decrease in all reactors after the feeding period ended. Still, the cellulases retained $30 \%$ (R1), 6\% (R2), and $8 \%$ (R3) of their activities measured prior to starvation after more than 60 days without feeding (Figure 2A). The decline in xylanase activities was slower compared to the decline in cellulase activities in all reactors. The retained xylanase activity was 59\% (R1), 19\% (R2), and 22\% (R3) after more than 60 days without feeding (Figure 2B).

Correlation with MPR. The Pearson's correlation test was used to indicate if the cellulase and xylanase activities were limiting the MPRs during the feeding period. The MPRs had a stronger correlation with cellulase activities $(r=0.66-0.80)$ compared to xylanase activities $(r=0.27-0.67)$ in all reactors, indicating the importance of cellulases for the MPR. Focusing on the first 1.5 HRT of straw feeding (day 11-41; five data points), where the MPRs generally increased: the cellulase and xylanase activities showed weak, negative correlation with MPR in R1 $(r=-0.34$ for cellulase, $r=-0.42$ for xylanase), compared to strong positive correlations of both cellulase and xylanase in R2 $(r=0.76$ for cellulase, $r=0.77$ for xylanase) and cellulase in R3 ( $r=0.95$ for cellulase and $r=0.05$ for xylanase). The MPR in R1 was thus not indicated to be limited by the activity of the measured hydrolases. In contrast, the MPR in R3 was strongly associated with the cellulase activity during the initial period. The cellulase activities were conversely highly correlated with MPRs in all reactors from day 46 and onward (eight data points for R2 and R3; nine data points for R1), with correlation coefficients of 0.89 (R1), 0.98 (R2), and 0.96 (R3).

\section{Microbial Community Compositions During Feeding}

Amplicon sequencing of the $16 \mathrm{~S}$ rRNA gene yielded highquality reads for 60 of the 70 sequenced samples. Samples generating less than 10,000 reads were removed from analysis based on a rarefaction curve (data not shown). A total of $3,269,716$ reads were generated across 60 samples and 9,273 ASVs, with an average of 54,495 $\pm 21,312$ reads per sample. Community richness (Chaol index) was measured at an average of $4,133 \pm 456$ ASVs per sample and was stable across 82 days of monitoring in the sampled duplicate reactors (data not shown). The highest richness was observed in the mesophilic R3 with an average of 4,503 \pm 306 ASVs per sample. The lowest richness was observed in the thermophilic manure-based R1, with an average of 3,722 \pm 234 ASVs per sample. Evenness (Shannon-Weaver index) in the reactors was measured at $6.51 \pm 0.29$ across 82 days of sampling and was highly similar between the three reactor types (6.49-6.53).

Correspondence Analysis (CA) was used to examine the development in microbial community composition in the three reactors during the feeding period (Supplementary Figure 1). Three distinct clusters representing the different duplicate reactors formed, indicating that distinct microbial communities developed from each inoculum. Tight clusters were formed for R1 and R3, while a larger development along the secondary axis was observed for R2. The specific microbial community compositions in the three duplicate reactors were explored using heatmaps (Supplementary Figures 2-4):

$R 1$. The relative abundance of several microbial populations increased from the start toward the end of the feeding period, including Cloacimonadaceae group W5 (3.5-18.1\% of total reads), "Candidatus Caldatribacterium" (1.4-7.5\% of total reads), Methanobacterium $(0.2-6.7 \%$ of total reads), and Methanosarcina $(0.5-4.8 \%$ of total reads). Other microbial 

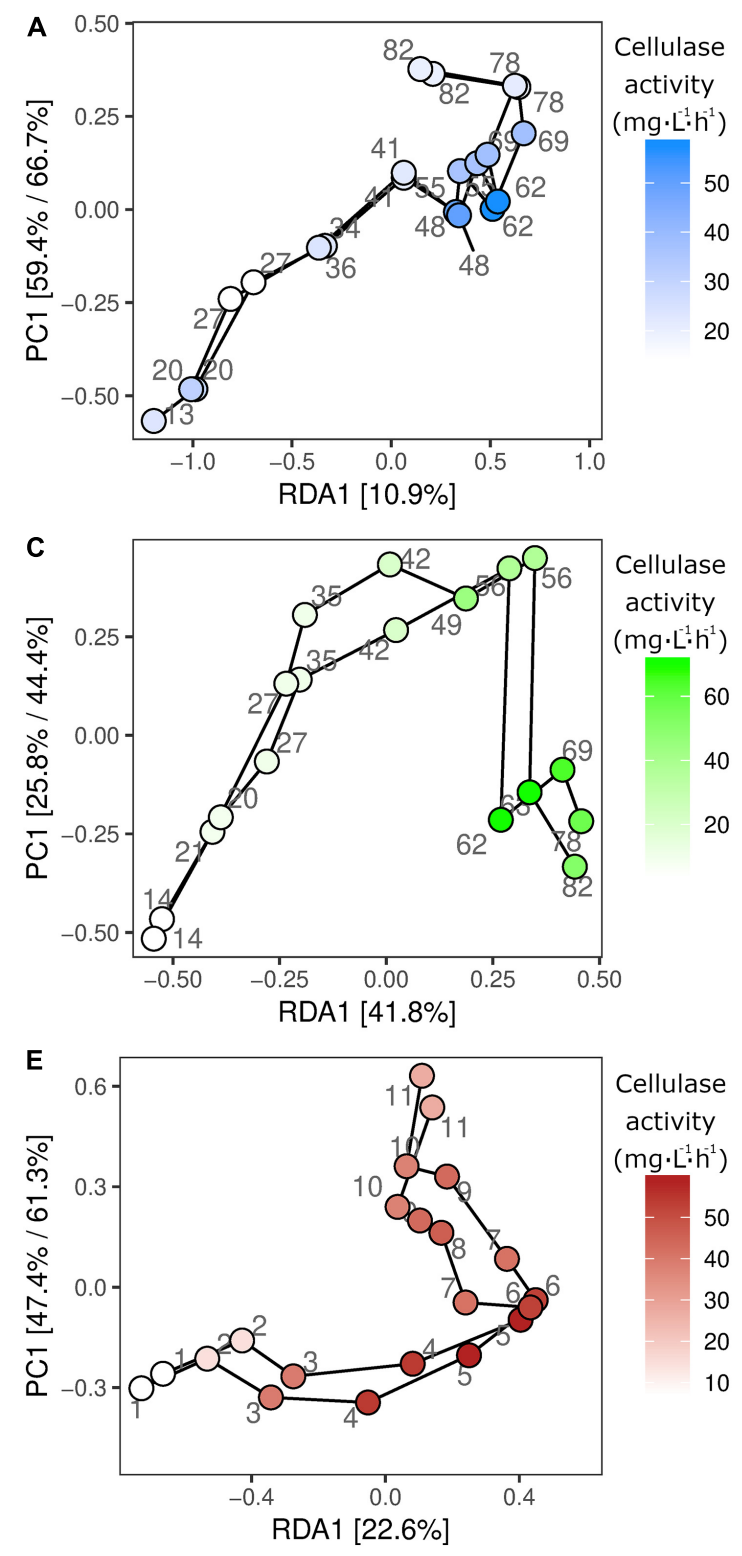
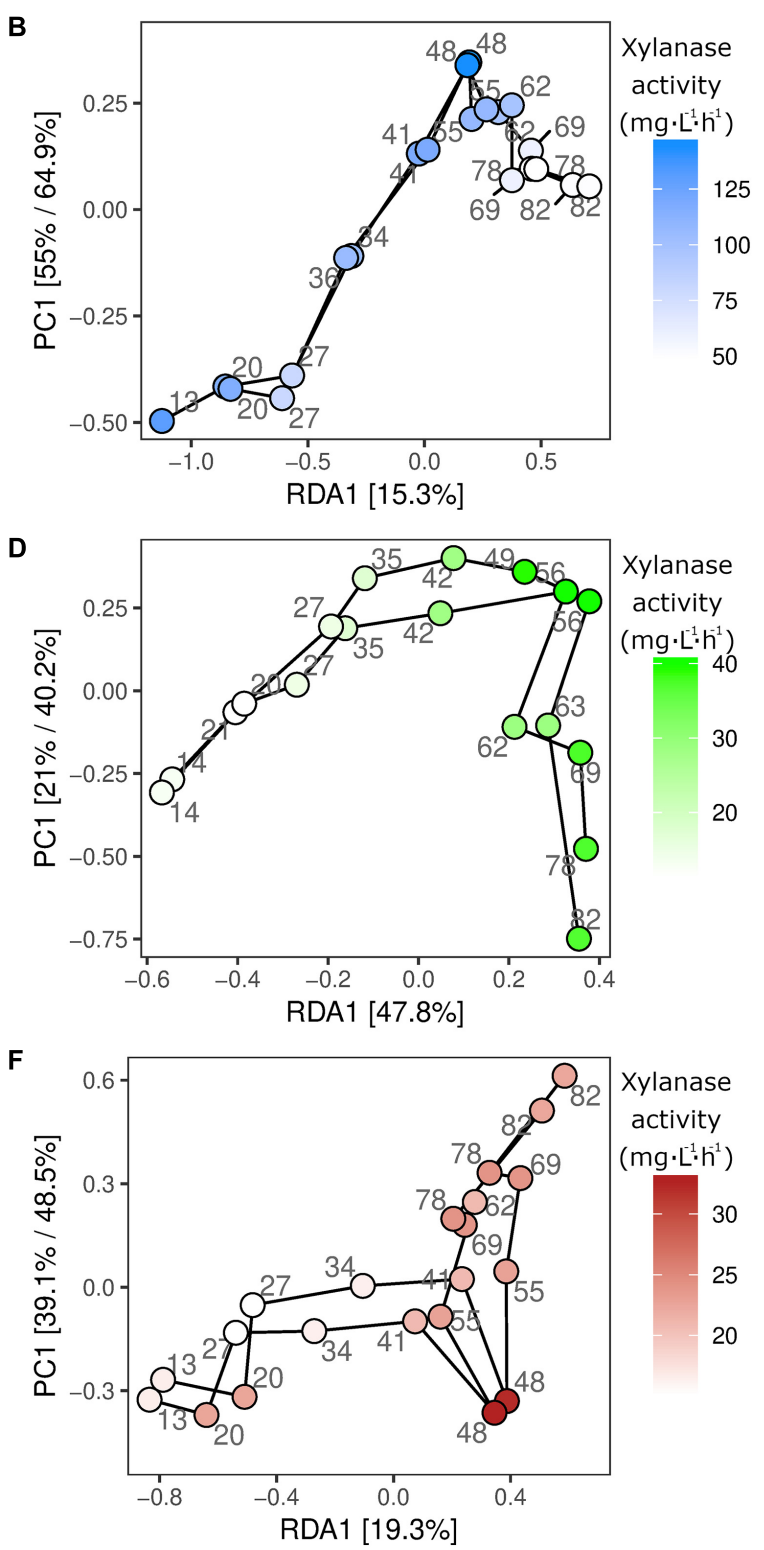

FIGURE 3 | Redundancy analysis. RDA analysis of the sampled duplicate reactors R1 (A,B), R2 (C,D), and R3 (E,F), constrained by either cellulase (A,C,E) or xylanase (B,D,F) activity. Samples are colored by enzymatic activity and a line is drawn between consecutive sampling points in the time series. The individual ASVs are shown on the models as gray dots. R1 is thermophilic, and R2 and R3 are mesophilic reactors.

groups decreased in abundance, including Defluviitoga (24.2-0.4\% of total reads), Clostridia order MBA03 (from 29.1 to $4.5 \%$ of total reads), and several uncharacterized microorganisms (Supplementary Figure 2).

$R 2$. The development of the microbial community in $\mathrm{R} 2$ was characterized by an increase in the relative abundance of Rikenellaceae group DMER64 (1.0-24.1\% of total reads), two representatives of Dysgonomonadaceae (0.7-9.8\% of total reads), Trichococcus (0-3.8\% of total reads), and Ruminiclostridium (0.2$3.7 \%$ of total reads). The relative abundance of Bacteroidetes representatives ST-12K33 and Bacteroidales UCG-001 had decreased by the end of the feeding period $(49.9-13.9 \%$ of total reads). However, the relative abundance of Bacteroidales UCG-001 increased initially and peaked at $19.7 \%$ by day 42 . Bacteroidales UCG-001 thus showed a similar developmental pattern as Enterococcus, whose relative abundance increased throughout the first 56 days (from 0.9 to 21.1\%) before reaching $3.4 \%$ by the end of the feeding period. The most abundant methanogenic populations belonged to Methanothrix and Methanosarcina, whose relative abundance, respectively, increased $(0.5-1.1 \%)$ and decreased (1.3-0.2\%) throughout the feeding period (Supplementary Figure 3).

R3. The relative abundance of the genus Trichococcus increased from $<0.1$ to $26.1 \%$ of total reads at day 48 but 
decreased to $9.9 \%$ of total reads at the end of the feeding period. Other taxonomic groups showing an increase in relative abundance were Bacteroidales group UCG-001 (5.1-18.7\% of total reads), "Candidatus Cloacimonas" (1.9-5.2\% of total reads), Ruminiclostridium (0.9-6.2\% of total reads at day 78 ), and Roseimarinus ( $<0.1-1.4 \%$ of total reads). In contrast, a decrease was observed in the relative abundance of Cloacimonadaceae group W5 (31.7-3.1\% of total reads), Bacteroidetes group vadinHA17 (4.4-1\% of total reads), Methanothrix (5.3-0.7\% of total reads), and Sedimentibacter (3-0.6\% of total reads) (Supplementary Figure 4).

\section{Linking Community Composition to Cellulase and Xylanase Activities}

The microbial community composition changes were examined in relation to the enzymatic profiles to identify individual subpopulations with potential hydrolytic functions. The potential link between microbial identity and hydrolytic function was established by correlating the changes in relative microbial abundance to those of the enzymatic activities (Figure 3). The correlation between enzymatic and microbial community profiles was significant in all duplicate reactors for both cellulase and xylanase. The strongest relationship between microbial community compositions and enzymatic activities was observed in R2 for both cellulase ( $\left.p=0.001, R^{2}=0.82\right)$, and xylanase $\left(p=0.001, R^{2}=0.89\right.$ ) (Figures 3C,D). A significant, but weaker relationship between the microbial community and the cellulase $\left(p=0.006, R^{2}=0.44\right)$ and xylanase $\left(p=0.009, R^{2}=0.46\right)$ activities was observed in R1 (Figures 3A,B). In R3, the cellulase activity ( $p=0.001, R^{2}=0.71$ ) had a stronger relationship to the microbial community compared to xylanase activity $(p=0.008$, $R^{2}=0.41$ ) (Figures 3E,F).

To extract ASVs with a similar development as the enzymatic activities and thereby identify taxonomic groups with potential hydrolytic function, the Kolmogorov-Smirnov test was applied to z-score normalized abundance and activity values. The largest number of ASVs of interest was observed in R2, where 258 and 293 ASVs showed similar development to the cellulase and xylanase activity, respectively. The number of identified ASVs ranged 61-152 ASVs in R1 and R3 (data not shown). The 25 ASVs with the strongest correlation to the cellulolytic and xylanolytic activities were selected from each reactor and enzyme combination for further examination (Tables 3-5). These candidates were of low abundance within the microbial community, having a relative abundance of $0.01-$ $0.5 \%$ of total reads per sample during the experimental period of 82 days (Supplementary Figure 5). In all reactor and enzyme combinations, the collective abundance of the candidate ASVs increased over time, except for R2 and cellulase (decrease from $1.14 \%$ at day 13 to $0.43 \%$ at day 78 ). The greatest increase in relative abundance was seen for R3 and cellulase, where the candidate ASVs made up 0.18 and $1.25 \%$ of total reads at day 13 and 78 , respectively.

The cellulase activity in R1 (Table 3) showed a strong correlation to the development of ASVs representing Clostridia order MBA03 (3 ASVs out of the 25 best candidates), and representatives of Lentimicrobiaceae (4), Ruminiclostridium (2), Proteiniphilum and Tepidanaerobacter (2). ASVs from Lentimicrobiaceae (4), and Ruminiclostridium (1) were also identified as candidates for the xylanase activity in R1, together with other representatives of Clostridia (5), Ruminicoccaceae (4), and Caldicoprobacter (2). In R2 (Table 4), the cellulase activity was most similar to the relative abundances of ASVs representing Pedosphaeraceae (4), Ruminococcaceae (6), and Ruminiclostridium (3). Candidate ASVs relating to the xylanase activity in R2 were overall from the same taxonomic groups, with additional representation of Spirochaetaceae (3) and Synergistaceae (2). Candidate organisms relating to the cellulase activity in R3 (Table 5) were mainly uncharacterized representatives of the phylum Acidobacteria (8) and the genera Ruminofilibacter (8) and Treponema (3). Treponema (5) was also observed among the candidates for xylanase activity in R3,

TABLE 3 | The 25 ASVs with behavior most similar to the enzymatic activities in the thermophilic R1.

\begin{tabular}{|c|c|c|c|}
\hline \multicolumn{2}{|c|}{ R1-Cellulase } & \multicolumn{2}{|c|}{ R1-Xylanase } \\
\hline Zotu102 & Ruminofilibacter & Zotu1334 & Lentimicrobiaceae \\
\hline Zotu1108 & Lentimicrobiaceae & Zotu1665 & Lentimicrobiaceae \\
\hline Zotu1109 & $\begin{array}{l}\text { Methanoculleus } \\
\text { thermophilus }\end{array}$ & Zotu1682 & Romboutsia \\
\hline Zotu1272 & Lentimicrobiaceae & Zotu1892 & Clostridiales \\
\hline Zotu1300 & Lentimicrobiaceae & Zotu2034 & Caldicoprobacter \\
\hline Zotu1334 & Lentimicrobiaceae & Zotu2056 & Ruminococcaceae \\
\hline Zotu1617 & Firmicutes & Zotu2076 & Lentimicrobiaceae \\
\hline Zotu1666 & Clostridiales Family XIII & Zotu2083 & Turicibacter sanguinis \\
\hline Zotu175 & Ca. Caldatribacterium & Zotu2195 & Dethiobacter \\
\hline Zotu1780 & Ruminococcaceae & Zotu2287 & Ruminococcaceae \\
\hline Zotu1829 & Bacteria & Zotu2358 & Turicibacter sanguinis \\
\hline Zotu1911 & Ruminiclostridium & Zotu2472 & $\begin{array}{l}\text { Ruminococcaceae } \\
\text { UCG-012 }\end{array}$ \\
\hline Zotu2065 & Caldicoprobacter & Zotu2921 & $\begin{array}{l}\text { Clostridia order } \\
\text { D8A-2 }\end{array}$ \\
\hline Zotu2128 & Clostridia & Zotu2927 & $\begin{array}{l}\text { Ruminococcaceae } \\
\text { UCG-012 }\end{array}$ \\
\hline Zotu2276 & $\begin{array}{l}\text { Ruminococcaceae } \\
\text { UCG-010 }\end{array}$ & Zotu3042 & $\begin{array}{l}\text { Clostridia order } \\
\text { D8A-2 }\end{array}$ \\
\hline Zotu2313 & Tepidanaerobacter & Zotu3158 & Caldicoprobacter \\
\hline Zotu2325 & Tepidanaerobacter & Zotu3185 & Caldicoprobacter \\
\hline Zotu2369 & Sedimentibacter & Zotu3296 & Clostridiales \\
\hline Zotu2400 & Pseudobacteroides & Zotu378 & Lentimicrobiaceae \\
\hline Zotu465 & Proteiniphilum & Zotu5675 & $\begin{array}{l}\text { Clostridia order } \\
\text { MBA03 }\end{array}$ \\
\hline Zotu4805 & $\begin{array}{l}\text { Clostridia order } \\
\text { MBA03 }\end{array}$ & Zotu6753 & Clostridiales Family XI \\
\hline Zotu510 & Proteiniphilum & Zotu6757 & $\begin{array}{l}\text { Clostridia order } \\
\text { MBA03 }\end{array}$ \\
\hline Zotu5675 & $\begin{array}{l}\text { Clostridia order } \\
\text { MBA03 }\end{array}$ & Zotu6994 & $\begin{array}{l}\text { Clostridia order } \\
\text { MBA03 }\end{array}$ \\
\hline Zotu6503 & $\begin{array}{l}\text { Clostridia order } \\
\text { MBA03 }\end{array}$ & Zotu8202 & $\begin{array}{l}\text { Clostridia order } \\
\text { MBA03 }\end{array}$ \\
\hline Zotu802 & Ruminiclostridium & Zotu9440 & Ruminiclostridium \\
\hline
\end{tabular}

The best possible taxonomic classification is given for each ASV. 
TABLE 4 | The 25 ASVs with behavior most similar to the enzymatic activities in the mesophilic R2.

\begin{tabular}{|c|c|c|c|}
\hline \multicolumn{2}{|c|}{ R2-Cellulase } & \multicolumn{2}{|c|}{ R2-Xylanase } \\
\hline Zotu1076 & Pedosphaeraceae & Zotu1019 & Dysgonomonadaceae \\
\hline Zotu1199 & Pedosphaeraceae & Zotu1190 & Pedosphaeraceae \\
\hline Zotu1241 & Pedosphaeraceae & Zotu1312 & Pedosphaeraceae \\
\hline Zotu1282 & Spirochaetaceae & Zotu1430 & Spirochaetaceae \\
\hline Zotu1312 & Pedosphaeraceae & Zotu1510 & Spirochaetaceae \\
\hline Zotu1559 & Ruminiclostridium & Zotu1647 & Spirochaetaceae \\
\hline Zotu1647 & Spirochaetaceae & Zotu1652 & Ruminiclostridium \\
\hline Zotu1734 & Dysgonomonadaceae & Zotu2071 & Acholeplasma \\
\hline Zotu2094 & Dysgonomonadaceae & Zotu2665 & Ruminiclostridium \\
\hline Zotu2330 & Ruminococcaceae & Zotu2800 & $\begin{array}{l}\text { Ruminococcaceae } \\
\text { UCG-010 }\end{array}$ \\
\hline Zotu2591 & Bacteroidales & Zotu2852 & Ruminococcaceae \\
\hline Zotu2648 & Ruminiclostridium & Zotu2888 & $\begin{array}{l}\text { Christensenellaceae } \\
\text { R-7 group }\end{array}$ \\
\hline Zotu2665 & Ruminiclostridium & Zotu2896 & $\begin{array}{l}\text { Ruminococcaceae } \\
\text { UCG-010 }\end{array}$ \\
\hline Zotu2784 & Ruminococcaceae & Zotu3770 & Acholeplasma \\
\hline Zotu2800 & $\begin{array}{l}\text { Ruminococcaceae } \\
\text { UCG-010 }\end{array}$ & Zotu3777 & Lachnospiraceae \\
\hline Zotu3428 & Ruminococcaceae & Zotu4154 & $\begin{array}{l}\text { Christensenellaceae } \\
\text { R-7 group }\end{array}$ \\
\hline Zotu352 & Sedimentibacter & Zotu4162 & Acholeplasma \\
\hline Zotu3654 & $\begin{array}{l}\text { Ruminococcaceae } \\
\text { UCG-010 }\end{array}$ & Zotu477 & Sedimentibacter \\
\hline Zotu3777 & Lachnospiraceae & Zotu5865 & Synergistaceae \\
\hline Zotu4054 & Ruminococcaceae & Zotu6002 & Bacteroidales \\
\hline Zotu4162 & Acholeplasma & Zotu7170 & Clostridiales Family XI \\
\hline Zotu4233 & Lachnospiraceae & Zotu7932 & Christensenellaceae \\
\hline Zotu7170 & Clostridiales Family XI & Zotu8126 & Peptococcaceae \\
\hline Zotu8216 & Clostridiales Family XI & Zotu8367 & Synergistaceae \\
\hline Zotu8367 & Synergistaceae & Zotu9261 & Thermovirga \\
\hline
\end{tabular}

The best possible taxonomic classification is given for each ASV.

together with representatives of "Candidatus Caldatribacterium" (2), Thermovirga (2), and Petrimonas mucosa (4).

\section{DISCUSSION}

The present study aimed to investigate the adaptation of cellulolytic and xylanolytic microbial communities in three different digester inocula after the addition of wheat straw as a lignocellulosic substrate. The enzymatic rate and microbial community profiles were used to identify candidate organisms with potential cellulolytic and xylanolytic activity.

\section{Cellulolytic and Xylanolytic Adaption Depends on Inoculum Origin}

Cellulose and hemicellulose are the degradable polymer groups in lignocellulose, and the rate of biogas production from lignocellulosic biomass is often considered limited by the activity of cellulases and hemicellulases (Gu et al., 2014). The consistently higher MPR in the thermophilic R1 (Figure 1) was therefore expected; partly because of the strong temperature-dependency of hydrolase kinetic rates (Ge et al., 2011), partly because R1 originates from an agricultural-based anaerobic digester, which is commonly reported as an efficient inoculum source for biogas production from lignocellulosic material (Koch et al., 2017; Liu et al., 2017). The increase in MPR (Figure 1) was accompanied by limited changes in cellulolytic (Figure 2A) and xylanolytic (Figure 2B) activities during the first 30 days of feeding (1.5 HRT), indicating that R1 initially possessed surplus hydrolytic capacity.

The significant decrease in R1 xylanase activity within the feeding period (Figure 2B) also indicates surplus xylanolytic potential, which potentially stems from a higher loading of xylan in the full-scale reactor from which the inoculum was sourced (Table 1). It is possible that other hemicellulases unable to cleave the MUF-linked substrate mimic have limited the MPR in situ, given the variety of hemicellulases potentially involved in lignocellulose degradation (Azman et al., 2015). Xylanase activity was selected as a representative for hemicellulose hydrolysis in the present study because xylan generally comprises a main constituent of the heterogeneous hemicellulose fraction in wheat straw (Tufail et al., 2018). The relevance of xylanolytic adaption

TABLE 5 | The 25 ASVs with behavior most similar to the enzymatic activities in the mesophilic R3.

\begin{tabular}{|c|c|c|c|}
\hline \multicolumn{2}{|c|}{ R3-Cellulase } & \multicolumn{2}{|c|}{ R3-Xylanase } \\
\hline Zotu1031 & Acidobacteria & Zotu1094 & Petrimonas mucosa \\
\hline Zotu1071 & $\begin{array}{l}\text { Clostridia order } \\
\text { MBA03 }\end{array}$ & Zotu1175 & Petrimonas mucosa \\
\hline Zotu1138 & Ca. Caldatribacterium & Zotu1215 & Treponema 2 \\
\hline Zotu1277 & Treponema 2 & Zotu1245 & Mesotoga infera \\
\hline Zotu1291 & Acidobacteria & Zotu1262 & Ca. Caldatribacterium \\
\hline Zotu1499 & Acidobacteria & Zotu1292 & Treponema 2 \\
\hline Zotu1555 & $\begin{array}{l}\text { Bacteroidales group } \\
\text { vadinHA17 }\end{array}$ & Zotu1366 & Ca. Caldatribacterium \\
\hline Zotu1779 & Acidobacteria & Zotu1468 & Pelotomaculum \\
\hline Zotu1978 & Acidobacteria & Zotu1476 & Petrimonas mucosa \\
\hline Zotu2070 & Syntrophorhabdus & Zotu1549 & $\begin{array}{l}\text { Bacteroidales group } \\
\text { vadinHA17 }\end{array}$ \\
\hline Zotu2110 & Acidobacteria & Zotu1555 & $\begin{array}{l}\text { Bacteroidales group } \\
\text { vadinHA17 }\end{array}$ \\
\hline Zotu2138 & Acidobacteria & Zotu1802 & Petrimonas mucosa \\
\hline Zotu2200 & Acidobacteria & Zotu1928 & Thermovirga \\
\hline Zotu2302 & Thermovirga & Zotu1974 & Thermovirga \\
\hline Zotu351 & Ruminofilibacter & Zotu1978 & Acidobacteria \\
\hline Zotu354 & Ruminofilibacter & Zotu2013 & Ca. Caldatribacterium \\
\hline Zotu426 & Ruminofilibacter & Zotu2096 & Marinimicrobia \\
\hline Zotu518 & Ruminofilibacter & Zotu2704 & Anaerolineaceae \\
\hline Zotu567 & Ruminofilibacter & Zotu2919 & Anaerolineaceae \\
\hline Zotu607 & Ruminofilibacter & Zotu3294 & $\begin{array}{l}\text { Cloacimonadaceae } \\
\text { group W5 }\end{array}$ \\
\hline Zotu648 & Ruminofilibacter & Zotu809 & Treponema 2 \\
\hline Zotu809 & Treponema 2 & Zotu815 & Clostridia order MBA03 \\
\hline Zotu933 & Mesotoga infera & Zotu936 & Treponema 2 \\
\hline Zotu950 & Ruminofilibacter & Zotu958 & Mesotoga infera \\
\hline Zotu981 & Treponema 2 & Zotu981 & Treponema 2 \\
\hline
\end{tabular}

The best possible taxonomic classification is given for each ASV. 
was supported by the activity profiles in R2 and R3 (Figure 2B), which increased steadily throughout the feeding period. The slow xylanolytic adaption in R2 and R3 aligns with observations from mesophilic anaerobic digestion of rice straw (Gu et al., 2014) and biomethane potential tests of different hemicellulose polymers, including pure xylan, in manure- and sludge-based digestates ( $\mathrm{Li}$ et al., 2018; Ma et al., 2019).

While the xylanase activity profiles developed differently in the three reactors, the cellulase activities were clearly stimulated by the addition of wheat straw in all reactors. However, the cellulase response time was significantly shorter in R3 compared to R1 and R2 (Figure 2A). The variation in response time likely reflects the differences in the microbial communities in the inocula. A tight coupling between microbial growth and cellulolytic activity has previously been reported in a pure-culture study of the Clostridia-affiliated Acetivibrio cellulolyticus (Saddler and Khan, 1980). The extended cellulolytic lag phase in R2 could hence result from a lower abundance of cellulolytic bacteria in the R2 inoculum, giving rise to pronounced growth and adaption in response to wheat straw addition. This hypothesis is supported by the strong correlations between the microbial community composition and enzymatic activities in R2. R2's need for a longer lag phase compared to R3 was also evidenced from the MPR, which was initially lower (Figure 1). The extended lag phase in R2 was unexpected since its inoculum originated from a full-scale digester fed with various types of lignocellulosic material. A potential explanation is the higher ammonium level in R2 compared to the other reactors (Table 1), as ammonia has previously been inversely correlated with the anaerobic degradation efficiency of both straw and cellulose (Sun et al., 2016).

The stimulation of cellulase activities was only temporary as these declined in all reactors within the feeding period (Figure 2A). The enzymatic assays were conducted at conditions that approached $V_{\max }$ so the reported enzyme activities are measures of a reactor's hydrolytic potential. The observed decreases in enzymatic activities consequently reflect a decrease in the concentration of active enzymes, potentially resulting from a down-regulation of the cellulase and xylanase expression. Microbial cellulase expression can both be induced and product inhibited by cellobiose and other sugar monomers (Adney et al., 1991; Kato et al., 2005) and depends on the nature of the lignocellulosic substrate (Badalato et al., 2017). Presence of acetate at concentrations of $1-2 \mathrm{~g} \cdot \mathrm{L}^{-1}$, as detected in both R2 and R3 (Table 2), has been found to reduce potential cellulolytic activity (Siegert and Banks, 2005) and growth of anaerobic cellulolytic Bacteroidaceae species (Saddler and Khan, 1979). However, based on the resolution of operational parameters recorded for R1, R2, and R3, we were unable to correlate the changes in enzyme potential with any of these parameters.

\section{Hydrolytic Adaption Results From Functional Homology in Diverse Microbes}

Analyses of the microbial community compositions revealed phylogenetically diverse communities in the three reactors
(Supplementary Figure 1). A previous study of microbial adaption to agricultural wastes found converging microbial community structures over time, with potential cellulosedegraders originating from the substrate (Liu et al., 2017). The phylogenetically different communities obtained in the present study stem from the inoculum-specific feed mixtures, while Liu et al. (2017) applied the same substrate mixture for all reactors. The identified potential hydrolytic bacteria suggest that the cellulolytic and xylanolytic activities are dominated by, but not constrained to, a finite number of reactor-specific phylogenetic groups.

Representatives of Lentimicrobiaceae and Clostridia order MBA03 were associated with cellulase activity in the thermophilic R1 (Table 3). These microbial groups have previously been linked to thermophilic anaerobic digestion of various substrates, including degradation of VFAs (Zheng et al., 2019), which are the primary products of lignocellulosic biomass degradation. Several of the identified Clostridia-affiliated ASVs were representatives of Ruminiclostridium, a taxonomic group that includes the known cellulose and xylan degrader, Ruminiclostridium cellulolyticum (Blouzard et al., 2010; Badalato et al., 2017). Caldicoprobacterassociated ASVs correlated to the xylanase activity in R1; this genus contains several species known to ferment xylan, including Caldicoprobacter oshimai, which was isolated from sheep feces (Yokoyama et al., 2010).

In the mesophilic R2, it was indicated that the ASVs affiliated with the Pedosphaeraceae and Clostridia class were important for the degradation of both cellulose and xylan (Table 4). Clostridia includes several known cellulolytic species (Azman et al., 2015). Pedosphaeraceae is not well-described in literature but has been hypothesized to participate in polysaccharide degradation during anaerobic digestion of food waste (Amha et al., 2019). Other species within the same phylum (Verrucomicrobia) possess a range of hydrolase-encoding genes (Martinez-Garcia et al., 2012). The R2 hydrolase correlations also identified several Clostridia representatives of Ruminococcaceae, which possesses a large genomic potential for cellulase and xylanase expression (Biddle et al., 2013).

In the sludge-based R3, several representatives of the Acidobacterium phylum, the genus Ruminofilibacter of the Bacteriodetes phylum, and the Treponema genus of the Spirochaetes phylum were indicated to be important for hydrolysis of the lignocellulosic wheat straw (Table 5). ASVs of the Acidobacterium and Ruminofilibacter were especially dominant in the cellulase correlations. Species within both taxonomic groups have accordingly been shown to possess cellulolytic and xylanolytic activity. Several isolated Acidobacterium species can use cellulose and xylan as carbon sources (Kielak et al., 2016), while Ruminofilibacter xylanolyticum is involved in xylan degradation (Nissilä et al., 2012). Ruminofilibacter species are generally poorly characterized in the literature. However, the strong correlation of several Ruminofilibacter ASVs with cellulase activity indicates their ability to either produce cellulases or live symbiotically with cellulase producers. Such symbiotic relationship has been proposed for the genus Treponema, which correlated with cellulase activity in R3. In a co-culture study, Treponema bryantii 
lived symbiotically with a cellulolytic strain of Bacteroides succinogenes (Stanton and Canale-Parola, 1980). The symbiotic co-culture increased cellulose degradation compared to that of the pure-culture $B$. succinogenes, despite $T$. bryantii not being able to grow on cellulose itself (Stanton and CanaleParola, 1980). A recent study assigned Spirochaetes sp., including Treponema, to be directly involved in xylan hydrolysis (Tokuda et al., 2018). A symbiotic relationship between Treponema and cellulolytic Fibrobacter species was explained by the former exposing cellulose structures for the latter by hydrolyzing hemicellulosic structures (Xie et al., 2018). The reported roles of Spirochaetaceae and Treponema in lignocellulose degradation aligns with the strong correlation of several Treponema ASVs to cellulase and xylanase activity in the sludge-based R3 (Table 5); and the correlation of Spirochaetaceae ASVs with cellulase and xylanase activity in the manure-based R2 (Table 4). Finally, the xylanase correlations in R3 identified ASVs related to Petrimonas mucosa, a species that possesses hydrolytic activity against a range of carbohydrate polymers, including cellulose and xylan (Hahnke et al., 2016).

The preceding analyses established a clear link between identified ASVs and the hydrolytic activity of their phylogenetic representatives. The results consequently reveal a potential of identifying candidate organisms with cellulolytic and xylanolytic activity by linking enzymatic assays and microbial community data. This combination constitutes a promising approach to further unravel the diverse hydrolytic communities in anaerobic digestion of lignocellulosic biomass by identifying key phylogenetic groups whose functional role can be confirmed and further analyzed through targeted studies. The enzymaticmicrobial approach can be combined with different metagenomic methods or advanced imaging techniques to confirm the possible link between microbial function and identity, as it has been done for other anaerobic digestion processes (Mosbæk et al., 2016; Fernando et al., 2019).

This study shows that phylogenetically different hydrolytic communities adapted from mesophilic and thermophilic inocula during anaerobic digestion of lignocellulosic wheat straw. The phylogenetic diversity was reflected in distinct activity profiles of cellulase and xylanase. Combined analyses of the microbial community and the cellulase and xylanase activity profiles were successfully used to identify potential cellulolytic and xylanolytic microorganisms. The identified microbes associated with enzymatic activity were reactor specific and included representatives of known hydrolytic groups such as Ruminofilibacter, Caldicoprobacter, Treponema, and a range of Clostridia-affiliated bacteria. The present study thus shows

\section{REFERENCES}

Achinas, S., Achinas, V., and Euverink, G. J. W. (2017). A technological overview of biogas production from biowaste. Engineering 3, 299-307. doi: 10.1016/J.ENG. 2017.03.002

Adney, W. S., Rivard, C. J., Shiang, M., and Himmel, M. E. (1991). Anaerobic digestion of lignocellulosic biomass and wastes - cellulases and related enzymes. Appl. Biochem. Biotechnol. 30, 165-183. doi: 10.1007/BF02921684 the potential application of enzymatic and microbial community studies to attain a deeper understanding of lignocellulosic biomass conversion in different anaerobic digestion inocula and to identify the potential hydrolytic organisms involved.

\section{DATA AVAILABILITY STATEMENT}

The sequencing datasets have been deposited in the European Nucleotide Archive (ENA) under project accession number PRJEB24105.

\section{AUTHOR CONTRIBUTIONS}

MJ, MD, JN, CF, LO, HM, and CK designed the study. KN and $\mathrm{ME}$ operated the reactors and conducted the enzymatic analyses under guidance by MJ, CF, and CK. NJ performed molecular analysis and conducted the bioinformatics analyses under guidance by JN. MJ, NJ, JN, and $\mathrm{MK}$ interpreted the data and wrote the manuscript with input from all coauthors. All authors contributed to the article and approved the submitted version.

\section{FUNDING}

This study was funded by the Innovation Fund Denmark Project "NomiGas" (1377-00040A), "Electrogas" (4106-00017B), and by Apple Inc. as part of the APPLAUSE bio-energy collaboration with Aarhus University. Work conducted in the JLN laboratory was supported by the Novo Nordisk Foundation (Grant no. NNF16OC0021818).

\section{ACKNOWLEDGMENTS}

We acknowledge the reactor operators at the full-scale plants for providing the inocula and the requested information regarding reactor operation.

\section{SUPPLEMENTARY MATERIAL}

The Supplementary Material for this article can be found online at: https://www.frontiersin.org/articles/10.3389/fmicb. 2021.645174/full\#supplementary-material

Ahring, B. K., Biswas, R., Ahamed, A., Teller, P. J., and Uellendahl, H. (2015). Making lignin accessible for anaerobic digestion by wet-explosion pretreatment. Bioresour. Technol. 175, 182-188. doi: 10.1016/j.biortech.2014. 10.082

Albertsen, M., Karst, S. M., Ziegler, A. S., Kirkegaard, R. H., and Nielsen, P. H. (2015). Back to basics - the influence of DNA extraction and primer choice on phylogenetic analysis of activated sludge communities. PLoS One 10:e132783. doi: 10.1371/journal.pone.0132783 
Amha, Y. M., Corbett, M., and Smith, A. L. (2019). Two-phase improves performance of anaerobic membrane bioreactor treatment of food waste at high organic loading rates. Environ. Sci. Technol. 53, 9572-9583. doi: 10.1021/acs.est. 9 b02639

Azman, S., Khadem, A. F., Lier, J. B., Van Zeeman, G., and Plugge, C. M. (2015). Presence and role of anaerobic hydrolytic microbes in conversion of lignocellulosic biomass for biogas production. Crit. Rev. Environ. Sci. Technol. 45, 2523-2564. doi: 10.1080/10643389.2015.1053727

Badalato, N., Guillot, A., Sabarly, V., Dubois, M., Pourette, N., Pontoire, B., et al. (2017). Whole proteome analyses on Ruminiclostridium cellulolyticum show a modulation of the cellulolysis machinery in response to cellulosic materials with subtle differences in chemical and structural properties. PLoS One 12:0170524. doi: 10.1371/journal.pone.0170524

Biddle, A., Stewart, L., Blanchard, J., and Leschine, S. (2013). Untangling the genetic basis of fibrolytic specialization by lachnospiraceae and ruminococcaceae in diverse gut communities. Diversity 5, 627-640. doi: 10.3390/d5030627

Blouzard, J. C., Coutinho, P. M., Fierobe, H. P., Henrissat, B., Lignon, S., Tardif, C., et al. (2010). Modulation of cellulosome composition in clostridium cellulolyticum: adaptation to the polysaccharide environment revealed by proteomic and carbohydrate-active enzyme analyses. Proteomics 10, 541-554. doi: 10.1002/pmic.200900311

Campanaro, S., Treu, L., Kougias, P. G., De Francisci, D., Valle, G., and Angelidaki, I. (2016). Metagenomic analysis and functional characterization of the biogas microbiome using high throughput shotgun sequencing and a novel binning strategy. Biotechnol. Biofuels 9:26. doi: 10.1186/s13068-016-0441-1

Carballa, M., Regueiro, L., and Lema, J. M. (2015). Microbial management of anaerobic digestion: exploiting the microbiome-functionality nexus. Curr. Opin. Biotechnol. 33, 103-111. doi: 10.1016/j.copbio.2015.01.008

Chao, A. (1984). Nonparametric estimation of the number of classes in a population. Scand. J. Stat. 11, 265-270.

Darrah, P. R., and Harris, P. J. (1986). A fluorometric method for measuring the activity of soil enzymes. Plant Soil 92, 81-88.

de Jonge, N., Davidsson, Å, la Cour Jansen, J., and Nielsen, J. L. (2020). Characterisation of microbial communities for improved management of anaerobic digestion of food waste. Waste Manag. 117, 124-135. doi: 10.1016/ j.wasman.2020.07.047

de Jonge, N., Moset, V., Møller, H. B., and Nielsen, J. L. (2017). Microbial population dynamics in continuous anaerobic digester systems during start up, stable conditions and recovery after starvation. Bioresour. Technol. 232, 313-320. doi: 10.1016/j.biortech.2017.02.036

De Vrieze, J. (2020). The next frontier of the anaerobic digestion microbiome: from ecology to process control. Environ. Sci. Ecotechnol. 3:100032. doi: 10.1016/j.ese. 2020.100032

De Vrieze, J., Pinto, A. J., Sloan, W. T., and Ijaz, U. Z. (2018). The active microbial community more accurately reflects the anaerobic digestion process: $16 \mathrm{~S}$ rRNA (gene) sequencing as a predictive tool. Microbiome 6:63. doi: 10.1186/s40168018-0449-9

Feng, L., Moset, V., Li, W., Chen, C., and Møller, H. B. (2017). In-situ injection of potassium hydroxide into briquetted wheat straw and meadow grass - effect on biomethane production. Bioresour. Technol. 239, 258-265. doi: 10.1016/j. biortech.2017.05.032

Fernando, E. Y., McIlroy, S. J., Nierychlo, M., Herbst, F. A., Petriglieri, F., Schmid, M. C., et al. (2019). Resolving the individual contribution of key microbial populations to enhanced biological phosphorus removal with raman-FISH. ISME J. 13, 1933-1946. doi: 10.1038/s41396-019-0399-7

Freeman, C., Liska, G., Ostle, N. J., Jones, S. E., and Lock, M. A. (1995). The use of fluorogenic substrates for measuring enzyme activity in peatlands. Plant Soil 175, 147-152. doi: 10.1007/BF02413020

Ge, H., Jensen, P. D., and Batstone, D. J. (2011). Relative kinetics of anaerobic digestion under thermophilic and mesophilic conditions. Water Sci. Technol. 64, 848-853. doi: 10.2166/wst.2011.571

Gu, Y., Chen, X., Liu, Z., Zhou, X., and Zhang, Y. (2014). Effect of inoculum sources on the anaerobic digestion of rice straw. Bioresour. Technol. 158, 149-155. doi: 10.1016/j.biortech.2014.02.011

Hahnke, S., Langer, T., Koeck, D. E., and Klocke, M. (2016). Description of proteiniphilum saccharofermentans sp. nov., petrimonas mucosa sp. nov. and fermentimonas caenicola gen. nov., sp. nov., isolated from mesophilic laboratory-scale biogas reactors, and emended description of the genus proteiniphilum. Int. J. Syst. Evol. Microbiol. 66, 1466-1475. doi: 10.1099/ijsem. 0.000902

Hassa, J., Maus, I., Off, S., Pühler, A., Scherer, P., Klocke, M., et al. (2018). Metagenome, metatranscriptome, and metaproteome approaches unraveled compositions and functional relationships of microbial communities residing in biogas plants. Appl. Microbiol. Biotechnol. 102, 5045-5063. doi: 10.1007/s00253018-8976-7

Hu, J., Arantes, V., and Saddler, J. N. (2011). The enhancement of enzymatic hydrolysis of lignocellulosic substrates by the addition of accessory enzymes such as xylanase: is it an additive or synergistic effect? Biotechnol. Biofuels 4:36. doi: 10.1186/1754-6834-4-36

Kato, S., Haruta, S., Cui, Z. J., Ishii, M., and Igarashi, Y. (2005). Stable coexistence of five bacterial strains as a cellulose-degrading community. Appl. Environ. Microbiol. 71, 7099-7106. doi: 10.1128/AEM.71.11.7099-7106.2005

Kielak, A. M., Barreto, C. C., Kowalchuk, G. A., van Veen, J. A., and Kuramae, E. E. (2016). The ecology of acidobacteria: moving beyond genes and genomes. Front. Microbiol. 7:744. doi: 10.3389/fmicb.2016.00744

King, G. M. (1986). Characterization of beta-glucosidase activity in intertidal marine sediments. Appl. Environ. Microbiol. 51, 373-380.

Koch, K., Lippert, T., and Drewes, J. E. (2017). The role of inoculum's origin on the methane yield of different substrates in biochemical methane potential (BMP) tests. Bioresour. Technol. 243, 457-463. doi: 10.1016/j.biortech.2017.06.142

Li, W., Khalid, H., Zhu, Z., Zhang, R., Liu, G., Chen, C., et al. (2018). Methane production through anaerobic digestion: participation and digestion characteristics of cellulose, hemicellulose and lignin. Appl. Energy 226, 12191228. doi: 10.1016/j.apenergy.2018.05.055

Liu, T., Sun, L., Müller, B., and Schnürer, A. (2017). Importance of inoculum source and initial community structure for biogas production from agricultural substrates. Bioresour. Technol. 245, 768-777. doi: 10.1016/j.biortech.2017. 08.213

Ma, S., Wang, H., Li, J., Fu, Y., and Zhu, W. (2019). Methane production performances of different compositions in lignocellulosic biomass through anaerobic digestion. Energy 189:116190. doi: 10.1016/j.energy.2019.116190

Martinez-Garcia, M., Brazel, D. M., Swan, B. K., Arnosti, C., Chain, P. S. G., Reitenga, K. G., et al. (2012). Capturing single cell genomes of active polysaccharide degraders: an unexpected contribution of verrucomicrobia. PLoS One 7:0035314. doi: 10.1371/journal.pone.0035314

Massey, F. J. (1951). The kolmogorov-smirnov test for goodness of fit. J. Am. Stat. Assoc. 46, 68-78. doi: 10.1080/01621459.1951.10500769

McIlroy, S. J., Kirkegaard, R. H., McIlroy, B., Nierychlo, M., Kristensen, J. M., Karst, S. M., et al. (2017). MiDAS 2.0: an ecosystem-specific taxonomy and online database for the organisms of wastewater treatment systems expanded for anaerobic digester groups. Database 2017, 1-9. doi: 10.1093/database/bax016

Mosbæk, F., Kjeldal, H., Mulat, D. G., Albertsen, M., Ward, A. J., Feilberg, A., et al. (2016). Identification of syntrophic acetate-oxidizing bacteria in anaerobic digesters by combined protein-based stable isotope probing and metagenomics. ISME J. 10, 2405-2418. doi: 10.1038/ismej.2016.39

Müller, B., Sun, L., Westerholm, M., and Schnürer, A. (2016). Bacterial community composition and fhs profiles of low - and high - ammonia biogas digesters reveal novel syntrophic acetate - oxidising bacteria. Biotechnol. Biofuels 9:48. doi: 10.1186/s13068-016-0454-9

Nissilä, M. E., Li, Y. C., Wu, S. Y., Lin, C. Y., and Puhakka, J. A. (2012). Hydrogenic and methanogenic fermentation of birch and conifer pulps. Appl. Energy 100, 58-65. doi: 10.1016/j.apenergy.2012.06.015

Noike, T., Endo, G., Chang, J.-E., Yaguchi, J.-I., and Matsumoto, J.-I. (1985). Characterization of carbohydrate degradation and the rate-limiting step in anaerobic digestion. Biotechnol. Bioeng. 27, 1482-1489. doi: 10.1002/bit. 260271013

$\mathrm{R}$ Core Team. (2016). A language and environment for statistical computing. Vienna: R Foundation for Statistical Computing

Regueiro, L., Veiga, P., Figueroa, M., Alonso-Gutierrez, J., Stams, A. J. M., Lema, J. M., et al. (2012). Relationship between microbial activity and microbial community structure in six full-scale anaerobic digesters. Microbiol. Res. 167, 581-589. doi: 10.1016/j.micres.2012.06.002

Rice, E. W., Baird, R. B., and Eaton, A. D. (2017). "Solids," in Standard Methods for the Examination of Water and Wastewater. Denver, CO: American Public Health Association, American Water Works Association, Water Environment Federation. 
Saddler, J. N., and Khan, A. W. (1979). Cellulose degradation by a new isolate from sewage sludge, a member of the bacteroidaceae family. Can. J. Microbiol. 25, 1427-1432. doi: 10.1139/m79-222

Saddler, J. N., and Khan, A. W. (1980). Cellulase production by acetivibrio cellulolyticus. Can. J. Microbiol. 26, 760-765. doi: 10.1139/m80-132

Sambusiti, C., Rollini, M., Ficara, E., Musatti, A., Manzoni, M., and Malpei, F. (2014). Enzymatic and metabolic activities of four anaerobic sludges and their impact on methane production from ensiled sorghum forage. Bioresour. Technol. 155, 122-128. doi: 10.1016/j.biortech.2013.12.055

Sawatdeenarunat, C., Surendra, K. C., Takara, D., Oechsner, H., and Khanal, S. K. (2015). Anaerobic digestion of lignocellulosic biomass: challenges and opportunities. Bioresour. Technol. 178, 178-186. doi: 10.1016/j.biortech.2014. 09.103

Scarlat, N., Dallemand, J.-F., and Fahl, F. (2018). Biogas: developments and perspectives in europe. Renew. Energy 129, 457-472. doi: 10.1016/j.renene.2018. 03.006

Shannon, C. E. (1948). A mathematical theory of communication. Bell Syst. Tech. J. 27, 379-423. doi: 10.1145/584091.584093

Siegert, I., and Banks, C. (2005). The effect of volatile fatty acid additions on the anaerobic digestion of cellulose and glucose in batch reactors. Process Biochem. 40, 3412-3418. doi: 10.1016/j.procbio.2005.01.025

Stanton, T. B., and Canale-Parola, E. (1980). Treponema bryantii sp. nov., a rumen spirochete that interacts with cellulolytic bacteria. Arch. Microbiol. 127, 145-156.

Sun, L., Liu, T., Müller, B., and Schnürer, A. (2016). The microbial community structure in industrial biogas plants influences the degradation rate of straw and cellulose in batch tests. Biotechnol. Biofuels 9, 1-20. doi: 10.1186/s13068016-0543-9

Tokuda, G., Mikaelyan, A., Fukui, C., Matsuura, Y., Watanabe, H., Fujishima, M., et al. (2018). Fiber-associated spirochetes are major agents of hemicellulose degradation in the hindgut of wood-feeding higher termites. Proc. Natl. Acad. Sci. U. S. A. 115, E11996-E12004. doi: 10.1073/pnas.1810550 115

Tufail, T., Saeed, F., Imran, M., Arshad, M. U., Anjum, F. M., Afzaal, M., et al. (2018). Biochemical characterization of wheat straw cell wall with special reference to bioactive profile. Int. J. Food Prop. 21, 1303-1310. doi: 10.1080/ 10942912.2018.1484759
Wall, D. M., Dumont, M., and Murphy, J. D. (2018). Green gas - Facilitating a future green gas grid through the production of renewable gas. IEA Bioenergy Task 372. Available Online at: https://www.ieabioenergy.com/wp-content/uploads/2018/ 04/green_gas_web_end.pdf [Accessed 7. April 2021]

Weiland, P. (2010). Biogas production: current state and perspectives. Appl. Microbiol. Biotechnol. 85, 849-860. doi: 10.1007/s00253-009-2246-7

Wickham, H. (2016). ggplot2: Elegant Graphics for Data Analysis. New York: Springer-Verlag.

Xie, X., Yang, C., Guan, L. L., Wang, J., Xue, M., and Liu, J. X. (2018). Persistence of cellulolytic bacteria fibrobacter and treponema after short-term corn stoverbased dietary intervention reveals the potential to improve rumen fibrolytic function. Front. Microbiol. 9:1363. doi: 10.3389/fmicb.2018.01363

Yokoyama, H., Wagner, I. D., and Wiegel, J. (2010). Caldicoprobacter oshimai gen. nov., sp. nov., an anaerobic, xylanolytic, extremely thermophilic bacterium isolated from sheep faeces, and proposal of caldicoprobacteraceae fam. nov. Int. J. Syst. Evol. Microbiol. 60, 67-71. doi: 10.1099/ijs.0.011379-0

Zhang, C., Yuan, Q., and Lu, Y. (2014). Inhibitory effects of ammonia on methanogen mcrA transcripts in anaerobic digester sludge. FEMS Microbiol. Ecol. 87, 368-377. doi: 10.1111/1574-6941.12229

Zheng, D., Wang, H.-Z., Gou, M., Nobu, M. K., Narihiro, T., Hu, B., et al. (2019). Identification of novel potential acetate-oxidizing bacteria in thermophilic methanogenic chemostats by DNA stable isotope probing. Appl. Microbiol. Biotechnol. 103, 8631-8645. doi: 10.1007/s00253-019-10078-9

Conflict of Interest: NJ is employed by the company NIRAS A/S.

The remaining authors declare that the research was conducted in the absence of any commercial or financial relationships that could be construed as a potential conflict of interest.

Copyright (C 2021 Jensen, de Jonge, Dolriis, Kragelund, Fischer, Eskesen, Noer, Møller, Ottosen, Nielsen and Kofoed. This is an open-access article distributed under the terms of the Creative Commons Attribution License (CC BY). The use, distribution or reproduction in other forums is permitted, provided the original author(s) and the copyright owner(s) are credited and that the original publication in this journal is cited, in accordance with accepted academic practice. No use, distribution or reproduction is permitted which does not comply with these terms. 